\title{
Lise Düzeyindeki Öğrencilerin Farklı Değişkenler Açısından Bilinçli Farkındalık Düzeylerinin İncelenmesi
}

\author{
Abdurrahman TOPAL ${ }^{1 *}$ (D) Mustafa YILMAZ ${ }^{2}$ (D), Müfit DAL $^{3}$ (D) \& \\ Fikret ALINCAK ${ }^{4}$ (D)
}

Gönderilme Tarihi:19 Aralık 2021

Kabul Tarihi: 29 Aralık 2021

DOI: $10.52974 /$ jena. 1041076

\section{$\ddot{O} z:$}

Bu çalışmanın amacı lise düzeyindeki ögrencilerin cinsiyet, sınıf düzeyi, spor branşı, taraftarı olduğu spor takımı, spor yapma durumu ve aile gelir düzeyi değişkenleri bakımından bilinçli farkındalık düzeylerinin belirlenmesi amaçlanmıştır. Bu bakımdan araştırmaya 140 kadın (\%52,4) 126 erkek (\%47,6) olmak üzere toplamda 266 lise düzeyinde öğrenci katılmıştır. Çalışmada veri toplama aracı olarak araştırmacılar tarafindan hazırlanan kişisel bilgi formu ve Orijinali Thienot ve ark. (2014) tarafindan geliştirilen, Türkçe uyarlaması Tingaz (2020) tarafindan yapılan 15 madde ve 3 alt boyuttan oluşan Sporcu Bilinçli Farkındalık (Mindfulness) Ölçeği kullanılmıştır. Araştırmada kapsamındaki bulgular incelendiğinde; cinsiyet değişkenine göre t-testi analizi yapılmıs ve yeniden odaklanma alt boyutunda anlamlı bir farklılık belirlenmiştir. Sinıf düzeyi, spor branşı, spor yapma durumu ve aile gelir düzeyi değişkenlerine göre tek yönlü varyans analizi (ANOVA) uygulanmış, analiz sonuçlarında sinıf düzeyi değişkenine göre farkındalık alt boyutunda, spor branşı ve spor yapma durumu değişkenine göre yeniden odaklanma alt boyutunda, aile gelir düzeyi değişkeninde yargllamama alt boyutunda anlamlı bir farklılık tespit edilmiștir. Katılımcıların taraftarı olduğu spor takımı değişkenine göre ölçeğin alt boyutlarında anlamlı bir farklılaşma görülmemiştir.

Anahtar Kelimeler: Bilinçli farkındalık, lise ögrencileri, spor.

Abstract:

The aim of this study is to determine the level of Mildfulness of highschool students in terms of genre, grade level, sport branch, team sports that they support, possibility of doing sport and their family income levels. In this regard, totally 266 high school level students including 140 girl $(\% 52,4)$ and 126 boy $(\% 47,6)$ participated to the research. In this study, personal information form prepared by researchers to collecting data and developed by Thienot etc. (2014) in original, translated to Turkish by Tingaz (2020)

\section{Atıf:}

Topal, A., Yılmaz, M., Dal, M. \& Alıncak, F. (2021) Lise düzeyindeki öğrencilerin farklı değişkenler açısından bilinçli farkındalık düzeylerinin incelenmesi. International Journal of Education and New Approaches, 4(2), 165-175. https://doi.org/10.52974/jena.1041076

\footnotetext{
${ }^{1}$ Gaziantep University, Turkey. Orcid ID: 0000-0002-1932-5126

${ }^{2}$ Gaziantep University, Turkey. Orcid ID: 0000-0002-0031-200X

${ }^{3}$ Gaziantep University, Turkey. Orcid ID: 0000-0002-6471-9423

${ }^{4}$ Gaziantep University, Turkey. Orcid ID: 0000-0003-3459-3441

*Corresponding Author: abdurrahmantopa10205@ hotmail.com
} 
consisting of 15 items and 3 sub-dimensions, Mildfulness Athlete scale has been used. When the findings within the scope of the research are examined; T-test analysis was performed according to the gender variable and a significant difference was determined in the refocus sub-dimension. One-way analysis of variance (ANOVA) was applied according to the variables of class level, sport branch, sporting status and family income level, and in the analysis results, in the awareness sub-dimension according to the class level variable, in the refocus subdimension according to the sport branch and sporting status variable, family income level. Variable, a significant difference was found in the sub-dimension of non-judgment. There was no significant difference in the subdimensions of the scale according to the variable of the sports team that the participants support.

Keywords: Mindfulness, highschool students, sport.

\section{GíRiş}

Bilinçli farkındalığın kökeni budizmden gelmektedir, bireyin dikkatini herhangi bir yargılama yapmadan yalnızca şu ana odaklaması ve onu kabul etme durumudur (Özyeşil, 2011). Şu an da gerçekleşen olaylara dikkati yöneltme süreci bilinçli farkındalık kavramı şeklinde tanımlanabilir. Yeni deneyimlere kapalı olmama, merak, kabul ve şu anda meydana gelen olaylar ile alakalı farkındalığı yakalamayı içine alır (Kabat-Zinn, 1990). Bilinçli farkındalık önceden yaşanan veya ileride yaşanma ihtimali olan olayların ve duyguların etkisi altında kalmadan şu anki zamanı kabul etmek ve onu tasdik etmek şeklinde ifade edilebilir (Bishop \& diğ., 2004). Bilinçli farkındalığın en sık kullanılan kavramlarından birisi şu anda yaşanılan zaman diliminde meydana gelen olayların farkına varılması ve dikkatli olunmasıdır (Brown \& Ryan, 2003). Bilinçli farkındalık dikkate odaklanmayı kapsayan bir metottur. Bilhassa yargılama yapmadan şu ana yoğunlaşmaktır. Bu bilinçli bir şekilde dikkatin geliştirilmesidir. Bilinçli farkındalık alıştırmalarının yönelimleri içerisinde açıklık, kavrama, merak ve yargılama yapmama yer almaktadır. Bilinçli farkındalıkta temel nokta, hissedilen veya meydana gelen durumların değiştirilme çabası olmadan olduğu gibi kabullenilmesidir (Nicholas \& Chambers, 2006). Bilinçli farkındalık bireyin kendisi, içerisinde bulunduğu grup ve başka insanlar ile alakalı yükssek bir bilinçliliğinin olmasıdır. Diğer bir deyişle bilinçli farkındalık, uyanık olma, kendisinin ve etrafındaki dünyanın farkında olma ve ona katılımda bulunarak tam ve bilinçli bir biçimde farkındalık durumunda yaşama biçimidir (McKee \& diğ., 2006). Bilinçli farkındalık (mindfulness-conciousness) dikkat ve farkındalığın şu anki zamanda tecrübe edilmesidir. Dikkatsizlik (mindlesness), dalgınlık, umrunda olmama ise göreceli biçimde bilinçli farkındalığın yokluğudur. Kişinin bir düşünceyi, hissi, dürtüyü, kabul etmediği bir duruma dikkatini vermeyi ya da onaylamayı red etmesidir (Brown \& Ryan 2013). Dikkatimizi seyrelterek şu anki duruma yoğunlaşıp yaşadığımız anın farkına varılması otomatik pilottan çıkmanın bir çözümüdür. Şu anki zamanın hissedilmesi bilinçli farkındalık metotlarıyla zaman içerisinde bir alışkanlık durumuna gelecektir. Dikkati sürekli olarak şu ana davet etmek ve anı yaşamak, iç ve dış alanda bulunanlar ile bağlantı halinde yaşamak, şu anda olmak anlamına gelir (Şahin, 2018). Bilinçli farkındalık kişilerin daha az tepkisel olmasına, olumlu, olumsuz ve objektif bir biçimde tüm tecrübeler ile bağlantıda bulunmasına katkı sağlayan ve psikolojik refah durumuna fayda sağlayan bir özelliktir (Germer, 2004). Bilinçli farkındalık hayatta tümüyle canlı ve uyanık kalmak adına bir şanstır. Bilinçli farkındalık şu anki durumlara karşı daha sakin kalmamıza yardım eden bir yetenektir ve pozitif, negatif ve nötr tüm tecrübelerimiz ile, kötü hissetmenin tüm durumlarını azaltması ve refah durumumuzu arttırması ile bağlantılıdır. Bilinçli bir biçimde farkında olmak bir uyanıştır ve bizler zaman zaman düşünce ve fikirlerimizi yaşadığımız zamana göre bilinçli bir biçimde yönlendirebiliriz bu durum ise umrunda olmama-dalgın olma (mindlessness) durumudur. Hatta bilinçli farkındalık hatırlamayı da kapsar, ancak bu hatıralarla yaşamak değil aksine bu durum dikkatimizi ve farkındalığımızı bütün benliğimiz ile onaylayıcı bir biçimde yaşadığımız zamandaki tecrübelere yöneltmektir, 
bu durum da anı bütünüyle hissetmemiz gerektiğini gösterir (Germer, 2005). Bilinçli farkındalığı fazla olan bireylerin olumlu hissetme, durumlara pozitif yaklaşma, akademik başarı ve sosyal yetenekleri gibi birtakım özellikleri daha fazla gelişmektedir (Karabacak ve Demir, 2017). Bu farkındalık durumu anında birey hislerini, düşüncelerini ve duygularını yargılamadan olduğu gibi kabullenir ve bu durumda içsel ve dişsal alanlara yoğunlaşmakta bu durumda bazı olumsuz halleri ve psikolojik faktörleri ortadan kaldırmaktadır (Baer, 2003). Bu açıdan bakıldığında bilinçli farkındalık özelliğine sahip bireyler, olumlu özelliklerini geliştirmeye çabalarken olumsuz özellikleri yani kendilerini kötü hissettiren özelliklerini kontrol edebileceklerdir. Hislerinin farkında olan bir kişi, günlük yaşamda daha etkili iletişim becerileri kurabilecek huzurlu ve üreten bir insan haline bürünecek ve bu sayede hayatını daha anlamlı duruma getirecektir (Koçak, 2002). Günlük yaşantısında bir sorunla karşılaşan ve kaygı hisseden ergenler bu hisler ile başa çıkmak için farklı yöntemlere başvururlar. Mesela; hislerini yüksek seviye de yaşadıkları ergenlik çağında birey, birtakım olaylara veya benlik problemlerine karşı kuşkulu veya kızgın hissedebilir. Kişinin o hisse karşı 'Neden bu şekil de hissediyorum?' Yetersizim-güçsüzüm' gibi hissetmesi yerine olaya karşı kendisini yargılamadan, durumu olduğu gibi kabullenmesiyle duygularını çok daha etkili biçimde yönetebilir. Bireyin duygularını kabul etmediği, kendi duygularına karşı olumsuz düşünceler hissettiği zamanlarda acısının arttığı görülmektedir. Bilinçli farkındalık bu tarz zamanlar da bireye farklı bir yol göstermektedir (Arslan, 2018).

\section{YÖNTEM}

\section{Araştırmanın Modeli}

Araştırmada mevcut olan bir durum ortaya çıkarılmak istendiği için betimsel tarama modeli kullanılmıştır. Betimsel tarama modelleri geçmişte ya da halen var olan bir durumu ortaya çıkarmayı hedefleyen araştırma modelidir. Bu bağlamda, araştırmaya konu olan faktörler olduğu gibi tanımlanarak ve uygun bir şekilde gözlemlenerek sonuçlandırılmıştır (Karasar, 2000).

\section{Araştırma Grubu}

Bu araştırmanın evrenini Gaziantep ilinin Şahinbey ilçesi oluştururken, örneklem grubunu Milli Eğitim Bakanlığına bağlı lise düzeyinde eğitim veren devlet okulları oluşturmaktadır. Araştırmaya 140 kadın 126 erkek olmak üzere toplamda 266 öğrenci katılmıştır.

\section{Veri Toplama Aracı}

Çalışmada araştırmacılar tarafından hazırlanan cinsiyet, sınıf düzeyi, spor branşı, taraftarı olduğu spor takımı, spor yapma durumu ve aile gelir düzeyini içeren kişisel bilgi formu ile sporcu bilinçli farkındalık ölçeği kullanılmıştır.

\section{Sporcu Bilinçli Farkındalık (Mindfulness) Ölçeği:}

Orijinali Thienot vd. (2014) tarafından geliştirilmiş, Türkçeye uyarlama çalışması Tingaz (2020) tarafından yapılmıştır. Ölçeğin farkındalık $(\alpha=0.81)$, yargılamama $(\alpha=0.70)$, ve yeniden odaklanma $(\alpha=0.77)$ olmak üzere 3 alt boyuttan ve her biri 5 maddeyi oluşturan toplam 15 maddeden oluşmaktadır. Ölçek 6'lı likert tipi bir yapıya sahip olup (1) "hemen hemen hiçbir zaman" ve (6) "hemen hemen her zaman" şeklinde puanlanmaktadır. Ölçeğin Cronbach Alpha iç tutarlık katsayısı $(\alpha=0.82)$ olarak hesaplandığı görülmüştür. 


\section{Verilerin Analizi}

Verilerin istatistiksel analizi için SPSS 22 paket programı kullanılmıştır. Verilerin normallik dağılımını belirlemek amacıyla çarpıklık ve basıklık (Skewness ve Kurtosis) değerleri incelenmiş, $-2,0+2,0$ arasında normal dağılım gösterebileceği tespit edilmiştir (George ve Mallery, 2010). Katılımcılar arasındaki anlamlı farklılıkları belirlemek amacıyla betimsel analiz yapılmıştır. Birbirinden bağımsız olan iki grup için t-testi, ikiden fazla gruplar için tek yönlü varyans analizi (ANOVA) testi uygulanmıştır. Tek yönlü varyans analizi (ANOVA) testi sonuçlarında gruplar arasındaki anlamlı farklılığ belirlemek amacıyla ikili karşılaştırma testlerinden tukey testi kullanılmıştır. Anlamlılık düzeyi 0,05 olarak kabul edilmiştir.

\section{BULGULAR}

Tablo 1. Sporcu Bilinçli Farkındalık Ölçeğinin (Mindfulness) Normallik Dağılım Sonuçları

\begin{tabular}{lccccccc}
\hline Faktör & $\mathbf{N}$ & Min & Max & $\overline{\mathbf{X}}$ & SS & Skewness & Kurtosis \\
\hline Farkındalık & 266 & 2,00 & 6,00 & 4,8880 &, 71634 & $\mathbf{- 1 , 0 8 5}$ & $\mathbf{1 , 8 9 0}$ \\
Yargılamama & 266 & 1,00 & 6,00 & 4,2226 &, 94407 & $\mathbf{- , 3 6 7}$ & $\mathbf{3 1 5}$ \\
Yeniden Odaklanma & 266 & 1,00 & 6,00 & 4,2925 &, 97564 & $\mathbf{- , 6 1 4}$ & $\mathbf{, 4 0 0}$ \\
\hline
\end{tabular}

Tablo 1'e göre Sporcu Bilinçli Farkındalık Ölçeğinin farkındalık, yargılamama ve yeniden odaklanma alt boyutlarının çarpıklık ve basıklık (Skewness ve Kurtosis) değerleri incelendiğinde $-2,0+2,0$ arasında normal dağılım gösterebileceği belirlenmiştir (George ve Mallery, 2010).

Tablo 2. Katılımcıların Cinsiyet Değişkenine Göre T-Testi Sonuçları

\begin{tabular}{lcccccc}
\hline Faktör & Cinsiyet & $\mathbf{N}$ & $\overline{\mathbf{X}}$ & $\mathbf{S S}$ & $\mathbf{t}$ & $\mathbf{p}$ \\
\hline Farkındalık & Kadın & 140 & 4,8186 &, 79636 & 7,512 &, 091 \\
& Erkek & 126 & 4,9651 &, 60930 & &, 663 \\
\hline Yargılamama & Kadın & 140 & 4,1986 &, 93023 &, 187 &, 96223 \\
& Erkek & 126 & 4,2492 & & & \\
\hline Yeniden Odaklanma & Kadın & 140 & 3,9943 &, 93561 & 1,376 & $\mathbf{0 0 0}$ \\
& Erkek & 126 & 4,6238 &, 91340 & & \\
\hline
\end{tabular}

Tablo 2'te belirtilen bulgulara göre sporcu bilinçli farkındalık ölçeğinin cinsiyet değişkenine göre t-testi sonuçları incelendiğinde; farkındalık ve yargılamama alt boyutunda anlamlı bir farklılık bulunmazken, yeniden odaklanma alt boyutunda anlamlı bir farklılık tespit edilmiştir.

Tablo 3. Katılımcıların Sınıf Düzeyi Değişkenine Göre Anova (Tek Yönlü Varyans) Analizi Sonuçları

\begin{tabular}{|c|c|c|c|c|c|c|c|}
\hline Faktör & $\begin{array}{c}\text { Sınıf } \\
\text { Düzeyi } \\
\end{array}$ & $\mathbf{N}$ & $\overline{\mathbf{X}}$ & SS & $\mathbf{F}$ & $\mathbf{p}$ & Tukey \\
\hline \multirow[t]{4}{*}{ Farkındalık } & 1. sinif & 27 & 4,8370 & ,60265 & 2,955 & ,033 & $2-4 *$ \\
\hline & 2. sinif & 50 & 4,6560 & ,77094 & & & \\
\hline & 3. sinif & 109 & 4,9009 & 68347 & & & \\
\hline & 4. sinif & 80 & 5,0325 &, 73360 & & & \\
\hline \multirow[t]{4}{*}{ Yargılamama } & 1. $\sin 1 f$ & 27 & 4,3037 & ,98663 & 1,287 & ,279 & \\
\hline & 2. sinif & 50 & 4,0360 & 1,06191 & & & \\
\hline & 3. sinif & 109 & 4,1908 & ,88292 & & & \\
\hline & 4. sinif & 80 & 4,3550 & ,92776 & & & \\
\hline \multirow[t]{4}{*}{ Yeniden Odaklanma } & 1. sinif & 27 & 4,3407 & ,83907 & 2,021 & ,111 & \\
\hline & 2. sinif & 50 & 4,0080 & ,97475 & & & \\
\hline & 3. sinif & 109 & 4,3083 & ,93829 & & & \\
\hline & 4. sinif & 80 & 4,4325 & 1,04697 & & & \\
\hline
\end{tabular}


Tablo 3'te belirtilen sonuçlara göre sporcu bilinçli farkındalık ölçeğinin sınıf düzeyi değişkenine göre tek yönlü varyans analizi sonuçları incelendiğinde; farkındalık alt boyutunda anlamlı bir farklılık belirlenmiştir. Yargılamama ve yeniden odaklanma alt boyutlarında anlamlı bir farklılık görülmemiştir.

Tablo 4. Katılımcıların Branş Değişkenine Göre Anova (Tek Yönlü Varyans) Analizi Sonuçları

\begin{tabular}{|c|c|c|c|c|c|c|c|}
\hline Faktör & Branş & $\mathbf{N}$ & $\overline{\mathbf{X}}$ & SS & $\mathbf{F}$ & $\mathbf{p}$ & Tukey \\
\hline \multirow[t]{5}{*}{ Farkındalık } & Basketbol & 49 & 4,7184 & ,87742 & 1,900 &, 111 & \\
\hline & Futbol & 106 & 4,9000 & ,63741 & & & \\
\hline & Voleybol & 76 & 4,8921 & ,68930 & & & \\
\hline & Hentbol & 13 & 4,8462 & ,92791 & & & \\
\hline & Atletizm & 22 & 5,2182 &, 55860 & & & \\
\hline \multirow[t]{5}{*}{ Yargllamama } & Basketbol & 49 & 4,2163 &, 74480 & ,035 & ,998 & \\
\hline & Futbol & 106 & 4,2151 & ,95606 & & & \\
\hline & Voleybol & 76 & 4,2500 & ,90752 & & & \\
\hline & Hentbol & 13 & 4,1538 & 1,38119 & & & \\
\hline & Atletizm & 22 & 4,2182 & 1,17093 & & & \\
\hline \multirow[t]{5}{*}{ Yeniden Odaklanma } & Basketbol & 49 & 4,0286 & ,86603 & 2,937 & ,021 & $1-2 *$ \\
\hline & Futbol & 106 & 4,5075 & ,96498 & & & \\
\hline & Voleybol & 76 & 4,1553 & ,89478 & & & \\
\hline & Hentbol & 13 & 4,0769 & 1,24241 & & & \\
\hline & Atletizm & 22 & 4,4455 & 1,17584 & & & \\
\hline
\end{tabular}

Tablo 4'te belirtilen sonuçlara göre sporcu bilinçli farkındalık ölçeğinin spor branşı değişkenine göre tek yönlü varyans analizi sonuçları incelendiğinde; farkındalık ve yargılamama alt boyutunda anlamlı bir farklılık görülmezken, yeniden odaklanma alt boyutunda anlamlı bir farklılık belirlenmiştir.

Tablo 5. Katılımcıların Taraftarı Olduğu Spor Takımı Değişkenine Göre Anova (Tek Yönlü Varyans) Analizi Sonuçları

\begin{tabular}{|c|c|c|c|c|c|c|c|}
\hline Faktör & Spor Takımı & $\mathbf{N}$ & $\overline{\mathbf{X}}$ & SS & $\mathbf{F}$ & p & Tukey \\
\hline \multirow[t]{4}{*}{ Farkındalık } & Fenerbahçe & 75 & 4,9467 & ,66441 & ,686 & ,561 & \\
\hline & Galatasaray & 116 & 4,8172 & ,76149 & & & \\
\hline & Beşiktaş & 63 & 4,9302 & ,72036 & & & \\
\hline & Anadolu Takımları & 12 & 4,9833 & ,55569 & & & \\
\hline \multirow[t]{4}{*}{ Yargilamama } & Fenerbahçe & 75 & 4,2880 & ,94967 & ,420 & ,739 & \\
\hline & Galatasaray & 116 & 4,1862 & ,94647 & & & \\
\hline & Beşiktaş & 63 & 4,2540 & ,87341 & & & \\
\hline & Anadolu Takımları & 12 & 4,0000 & 1,27920 & & & \\
\hline \multirow[t]{4}{*}{ Yeniden Odaklanma } & Fenerbahçe & 75 & 4,1893 & ,96080 & 1,527 & ,208 & \\
\hline & Galatasaray & 116 & 4,2466 & 1,01480 & & & \\
\hline & Beşiktaş & 63 & 4,4159 & ,93277 & & & \\
\hline & Anadolu Takımları & 12 & 4,7333 &, 81054 & & & \\
\hline
\end{tabular}

Tablo 5'te belirtilen bulgulara göre sporcu bilinçli farkındalık ölçeğinin katılımcıların taraftarı olduklar spor takımı değişkenine göre tek yönlü varyans analizi sonuçları incelendiğinde; farkındalık, yargılamama ve yeniden odaklanma alt boyutlarında anlamlı bir farklılık tespit edilmemiştir. 
Tablo 6. Katılımcıların Spor Yapma Durumları Değişkenine Göre Anova (Tek Yönlü Varyans) Analizi Sonuçları

\begin{tabular}{|c|c|c|c|c|c|c|c|}
\hline Faktör & Spor Yapma Durumu & $\mathbf{N}$ & $\overline{\mathbf{X}}$ & SS & $\mathbf{F}$ & $\mathbf{p}$ & Tukey \\
\hline \multirow[t]{3}{*}{ Farkındalık } & Hareketsiz yaşam tarzı & 52 & 4,7346 &, 74804 & 1,721 &, 181 & \\
\hline & $\begin{array}{l}\text { Haftada bir gün yapılan } \\
\text { sportif faaliyet (Yürüyüş, } \\
\text { halı saha, yüzme vb.) }\end{array}$ & 146 & 4,9479 & ,68965 & & & \\
\hline & $\begin{array}{l}\text { Düzenli yapılan spor } \\
\text { (takım antrenmanları, } \\
\text { fitness vb.) }\end{array}$ & 68 & 4,8765 & ,74033 & & & \\
\hline \multirow[t]{3}{*}{ Yargılamama } & Hareketsiz yaşam tarzı & 52 & 4,3308 & 88728 & ,448 & 639 & \\
\hline & $\begin{array}{l}\text { Haftada bir gün yapılan } \\
\text { sportif faaliyet (Yürüyüş, } \\
\text { halı saha, yüzme vb.) }\end{array}$ & 146 & 4,1863 & ,93208 & & & \\
\hline & $\begin{array}{l}\begin{array}{l}\text { Düzenli yapılan spor } \\
\text { (takım }\end{array} \\
\text { fitness vb.) }\end{array}$ & 68 & 4,2176 & 1,01672 & & & \\
\hline \multirow{3}{*}{$\begin{array}{l}\text { Yeniden } \\
\text { Odaklanma }\end{array}$} & Hareketsiz yaşam tarzı & 52 & 3,7692 & ,99124 & 13,185 & ,000 & $1-2 *$ \\
\hline & $\begin{array}{l}\text { Haftada bir gün yapılan } \\
\text { sportif faaliyet (Yürüyüş, } \\
\text { halı saha, yüzme vb.) }\end{array}$ & 146 & 4,3123 & ,88978 & & & $1-3 *$ \\
\hline & $\begin{array}{l}\text { Düzenli yapılan spor } \\
\text { (takım antrenmanları, } \\
\text { fitness vb.) }\end{array}$ & 68 & 4,6500 & ,98002 & & & \\
\hline
\end{tabular}

Tablo 6'da belirtilen sonuçlara göre sporcu bilinçli farkındalık ölçeğinin spor yapma durumu değişkenine göre tek yönlü varyans analizi sonuçları incelendiğinde; farkındalık ve yargılamama alt boyutunda anlamlı bir farkl1lık görülmezken, yeniden odaklanma alt boyutunda anlamlı bir farklılık tespit edilmiştir.

Tablo 7. Katılımcıların Aile Gelir Düzeyi Değișkenine Göre Anova (Tek Yönlü Varyans) Analizi Sonuçları

\begin{tabular}{|c|c|c|c|c|c|c|c|}
\hline Faktör & Aile Gelir Düzeyi & $\mathbf{N}$ & $\overline{\mathbf{X}}$ & SS & $\mathbf{F}$ & $\mathbf{p}$ & Tukey \\
\hline \multirow[t]{4}{*}{ Farkındalık } & $1500 \mathrm{TL}$ ve altı & 44 & 4,7727 & ,80532 & 1,795 & 149 & \\
\hline & $\begin{array}{c}1501-3000 \mathrm{TL} \\
\text { aras1 }\end{array}$ & 131 & 4,8382 &, 72456 & & & \\
\hline & $\begin{array}{c}\text { 3001-4500 TL } \\
\text { aras1 }\end{array}$ & 64 & 4,9750 & ,65756 & & & \\
\hline & 4500 TL ve üzeri & 27 & 5,1111 & ,61603 & & & \\
\hline \multirow[t]{4}{*}{ Yargilamama } & 1500 TL ve alt1 & 44 & 4,4455 & 1,04758 & 3,242 & ,023 & $2-4^{*}$ \\
\hline & $\begin{array}{c}1501-3000 \mathrm{TL} \\
\text { aras1 }\end{array}$ & 131 & 4,0656 &, 87721 & & & \\
\hline & $\begin{array}{c}\text { 3001-4500 TL } \\
\text { aras1 }\end{array}$ & 64 & 4,2500 & 1,01042 & & & \\
\hline & 4500 TL ve üzeri & 27 & 4,5556 &, 78903 & & & \\
\hline \multirow[t]{4}{*}{ Yeniden Odaklanma } & 1500 TL ve alt1 & 44 & 4,2682 & ,97974 & 1,256 & ,290 & \\
\hline & $\begin{array}{c}1501-3000 \mathrm{TL} \\
\text { aras1 }\end{array}$ & 131 & 4,1939 & 1,01828 & & & \\
\hline & $\begin{array}{c}\text { 3001-4500 TL } \\
\text { aras1 }\end{array}$ & 64 & 4,4219 & ,89309 & & & \\
\hline & 4500 TL ve üzeri & 27 & 4,5037 & ,92715 & & & \\
\hline
\end{tabular}

Tablo 7'de belirtilen sonuçlara göre sporcu bilinçli farkındalık ölçeğinin aile gelir değişkenine göre tek yönlü varyans analizi sonuçları incelendiğinde; farkındalık ve yeniden odaklanma alt boyutunda anlamlı bir farklılık görülmezken, yargılamama alt boyutunda anlamlı bir farklılık belirlenmiştir. 


\section{TARTIŞMA VE SONUÇ}

Bilinçli farkındalık ölçeğinin cinsiyet değişkenine göre t-testi sonuçları incelendiğinde; ölçeğin yeniden odaklanma alt boyutunda anlamlı bir farklılık olduğu tespit edilmiştir. Yeniden odaklanma alt boyutunun ortalama puanlarına bakıldığında erkek katılımcıların ortalama puanlarının kadın katılımcıların ortalama puanından daha yüksek olduğu, anlamlı bulunan faklılaşmanın erkek katılımcılar lehine sonuçlandığı görülmektedir. Bu farklılığın; erkek katılımcıların müsabaka anında gergin oldukları durumda, yorgunluk durumlarında veya daha iyi performans gösterebilmelerine yardımcı olacak herhangi bir durumda yeniden odaklanma performanslarının kadın katılımcılara göre daha yüksek olmasından kaynaklandığı düşünülmektedir. Alan yazın incelendiğinde araştırmamızı destekleyen çalışmaların olduğu belirlenmiştir. Vural ve Okan (2021) tarafından "atıcılık spor branşları üzerine bir araştırma" isimli çalışmalarında sporcuların cinsiyet değişkenine göre yeniden odaklanma alt boyutunda, erkek katılımcılar lehine anlamlı bir faklılık tespit edilmesi araştırmamızı destekler niteliktedir. Çalışmamızı destekler nitelikteki bir diğer çalışma Kesler (2020) tarafından yapılmıştır. Elit güreşçilerle yapılan araştırmada erkek sporcuların ortalama puanlarının kadın sporcuların ortalama puanlarından daha yüksek bulunması çalışmamızla paralellik göstermektedir.

Bilinçli farkındalık ölçeğinin sınıf düzeyi değişkenine göre tek yönlü varyans analizi sonuçların incelendiğinde; ölçeğin farklındalık alt boyutunda anlamlı bir farklılık olduğu görülmektedir. $\mathrm{Bu}$ farklılığın hangi gruplar arasında olduğunu belirlemek amacıyla ikili karşılaştırma testlerinden olan tukey testi uygulanmıştır. Bu sonuçlara göre anlamlı bulunan farklılaşmanın lise ikinci sınıfta öğrenim gören katılımcılar ile lise dördüncü sınıfta öğrenim gören katılımcılar arasında olduğu, lise son sınıftaki katılımcıların ortalama puanlarının lise ikinci sınıftaki katılımcıların ortalama puanlarından yüksek olduğu tespit edilmiştir. Bu farklılaşmanın lise son sınıftaki öğrencilerin, alt sınıflarda öğrenim gören öğrencilere göre kaygı, heyecan, düşünce ve duygu bakımından farkındalık düzeylerinin daha yüksek olmasından dolayı kaynaklandığ düşünülmektedir. Literatür incelendiğinde çalışmamızı destekler nitelikte bir bulguya rastlanmamaktadır. Fakat sınıf düzeyine göre farklılaşmayan çalışmalar mevcuttur. Aygün (2020) tarafından lise öğrencileri üzerindeki yapılan çalışmada sınıf düzeyleri arasında anlamlı bir farklılık olmadığı görülmektedir. Çalışılan konuyla ilgili ileriki çalışmalarda sınıf düzeyi değişkenine daha sık yer verilmesi gerektiği düşünülmektedir.

Bilinçli farkındalık ölçeğinin spor branşları değişkenine göre tek yönlü varyans analizi sonuçların incelendiğinde; yeniden odaklanma alt boyutunda anlamlı bir farklılık olduğu belirlenmiştir. Hangi gruplar arasında farklılık olduğunu belirlemek amacıyla ikili karşılaştırma testlerinden olan tukey testi uygulanmış, basketbol ve futbol branşlarında bir farklılaşmanın olduğu, futbol branşının ortalamasının basketbol branşının ortalamasından daha yüksek olduğu verilen sonuçlarda görülmüştür. Bu sonucun futbol branşına sahip olan katılımcıların spor müsabakalarında daha iyi performans gösterebilecek durumlara yeniden odaklanma seviyelerinin basketbol branşına sahip olan katılımcılardan daha yüksek olmasından kaynaklandığı düşünülmektedir. Literatür incelendiğinde çalışmamızı destekler nitelikte bir bulguya rastlanmamaktadır. Fakat spor branşları değişkenine göre farklılaşmayan çalışmalar mevcuttur. Tingaz (2020) tarafından yapılan spor bilimleri fakültesinde öğrenim gören sporcu öğrenciler üzerindeki bir çalışmada, spor branşları arasında anlamlı bir farklılaşmanın bulunmadığı bir sonuç görülmektedir. Yapılacak olan ileriki çalışmalarda spor branşları değişkenine daha sık yer verilmesi gerektiği düşünülmektedir. 
Bilinçli farkındalık ölçeğinin katılımcıların spor yapma durumu değişkenine göre tek yönlü varyans analizi sonuçların incelendiğinde; yeniden odaklanma alt boyutunda anlamlı bir farklılık belirlenmiştir. Hangi gruplar arasında farklılık olduğunu belirlemek amacıyla ikili karşılaştırma testlerinden olan tukey testi uygulanmış, hareketsiz yaşam tarzını benimseyen katılımcılar ile haftada bir gün veya düzenli olarak spor yapan katılımcılar arasında olduğu belirlenmiştir. Düzenli olarak spor yapan katılımcıların ortalama puanları, hareketsiz yaşam tarzını benimseyen katılımcılar ile hafta bir gün sportif faaliyette bulunan katılımcılardan daha yüksek olduğu görülmüştür. Literatür incelendiğinde çalışmamızı destekler nitelikte bir bulguya rastlanmamaktadır. Fakat spor yapma durumlarına göre farklılaşmanın olmadığı çalışmalar mevcuttur. Maraşlı (2018) tarafından yapılan genç hentbolcular üzerindeki çalışmada katılımcıların antrenman sıklığı değişkeninde anlamlı bir farklılığın bulunmadığı görülmüştür. Yapılacak olan ileriki çalışmalarda spor yapma durumu veya antrenman sıklığ değişkenine daha sık yer verilmesi gerektiği düşünülmektedir.

Bilinçli farkındalık ölçeğinin katılımcıların aile gelir düzeyi değişkenine göre tek yönlü varyans analizi sonuçların incelendiğinde; yargilamama alt boyutunda anlamlı bir farklılık olduğu görülmüş̧ür. Hangi gruplar arasında farklılık olduğunu belirlemek amacıyla ikili karşılaştırma testlerinden olan tukey testi uygulanmış, $4500 \mathrm{TL}$ ve üzeri gelir düzeyine sahip katılımcılar ile 1500-3000 TL arası gelir düzeyine sahip katılımcılar arasında olduğu belirlenmiştir. $4500 \mathrm{TL}$ ve üzerinde gelir düzeyine sahip katılımcıların ortalama puanlarının daha yüksek olduğu görülmüş̧ür. Alan yazın incelendiğinde anlamlı bir farklılığın olmadığı çalışmalar mevcuttur. Aygün (2020) tarafından yapılan bir araştırmada ailelerin gelir düzeyleri arasında anlamlı bir farklılaşmanın bulunmadığı görülmüştür. Ölçeğin farkındalık ve yeniden odaklanma alt boyutlarında anlamlı bir farklılık tespit edilmemiştir.

Sonuç olarak bilinçli farkındalık ölçeğinin cinsiyet, sınıf düzeyi, spor branşı, spor yapma durumu ve aile gelir düzeyi değişkenlerinde, katılımcılar arasında anlamlı bir farklılığın tespit edildiği görülmüştür. Katılımcıların taraftarı oldukları spor takımı değişkeninde ise anlamlı bir farklılaşmanın olmadığı belirlenmiştir. Yapılacak olan ileriki çalışmalarda değişken sayılarının arttırılması daha belirgin ve daha ayrıntılı sonuçlar ortaya koyacağı için bilinçli farkındalık çalışmaları açısından önem arz etmektedir.

\section{Etik Metin}

$\mathrm{Bu}$ makalede araştırma ve yayın etiği kuralları takip edilmektedir. Makale ile ilgili her türlü ihlalin sorumluluğu yazar/yazarlara aittir.

\section{KAYNAKLAR}

Arslan, I. (2018). Bilinçli farkındalık, depresyon düzeyleri ve algılanan stres arasındaki ilişki. Birey ve Toplum Sosyal Bilimler Dergisi, 8(2), 73-86.

Aygün, M. (2020). Spor lisesi ve düz lise öğrencilerinin kariyer kaygısı ve bilinçli farkındalıklarının incelenmesi. Atatürk Üniversitesi Bedene Ë̆itimi ve Spor Dergisi, 22(4), 90-100.

Baer, R. B. (2003). Mindfulness training as a clinical intervention: A conceptual and empirical review. Clinical Psychology: Science and Practice, 10(2), 125-143.

Bishop, S. R., Lau, M., Shapiro, S., Carlson, L., Anderson, N. D., Carmody, J. \& Devins, G. (2004). Mindfulness: A proposed operational definition. Clinical Psychology: Science and Practice, 11(3), 230-241.

Brown, K. M.\& Ryan, R. M. (2003). The benefits of being present: Mindfulness and its role in psychological wellbeing. Journal of Personality and Social Psychology, 84(4), 822-848. 
George, D.\& Mallery, M. (2010). SPSS for windows step by step: a simple guide and reference, 17.0 update. Pearson

Germer, C. (2004). What is mindfulness. Insight Journal, (22), 24-29.

Germer, C. K., Siegel, R. D., \& Fulton, P. R. (2005). Mindfulness and psychotherapy. Guilford.

Halliwell, E. (2010). Mindfulness-Report 2010. Mental Health Foundation.

Kabat-Zinn, J. (1990). Full catastrophe living: using the wisdom of your mind to face stress, pain and ilness. Dell Publishing.

Karasar N. (2000). Bilimsel araştırma yöntemleri. Nobel Yayın Dağıtım.

Karabacak A., Demir M. (2017). Özerklik, bağlanma stilleri, bilinçli farkındalık ve duygu düzenleme arasındaki ilişkilerin incelenmesi. Bayburt Ĕgitim Fakültesi Dergisi, 12(23), 271-291.

Kesler, E. (2020). Elit güreşçilerde bilinçli farkindalık, sürekli optimal performans duygu durumu, spora katılım motivasyonu ve stres düzeylerinin incelenmesi [Yayınlanmamış yüksek lisans tezi]. Sakarya Uygulamalı Bilimler Üniversitesi, Lisansüstü Eğitim Enstitüsü, Sakarya, Türkiye.

Koçak, R. (2002). Aleksitimi: Kuramsal çerçeve tedavi yaklaşımları ve ilgili araştırmalar. Ankara Üniversitesi Eğitim Bilimleri Fakültesi Dergisi, (35), 185-197.

Maraşlı, H. (2018). Genç Hentbolcuların Zihinsel Dayanıkllılk Ve Bilinçli Farkındalık Düzeyleri Arasındaki İlişkinin Incelenmesi [Yayınlanmamış yüksek lisans tezi]. Kütahya Dumlupınar Üniversitesi, Sosyal Bilimler Enstitüsü, Kütahya, Türkiye.

McKee A., Johnston F. \& Massimilian, R. (2006). Mindfulness, hope and compassion: A leader's road map to renewal. Ivey Business Journal, 70(5), 1-5.

Nicholas, B. A. \& Chambers, R. (2006) Mindfulness-based psychotherapies. A review of conceptual foundations, empirical evidence and practical considerations. Australian and New Zealand Journal of Psychiatry, 40(4), 285294.

Özyeşil, Z. (2011). Özanlayış ve bilinçli farkındalık. Maya Akademi Yayıncılık.

Şahin, A. (2018). Üniversite öğrencilerinde bilinçli farkındalık ile yaşam doyumu ve iyi oluş arasındaki ilişkiler [Yayınlanmamış yüksek lisans tezi]. Üsküdar Üniversitesi, Sosyal Bilimler Enstitüsü, İstanbul, Türkiye.

Tingaz, E. O. (2020). Sporcu bilinçli farkındalık (Mindfulness) ölçeği: Türkçeye uyarlama, geçerlik ve güvenirlik çalışması. SPORMETRE Beden Eğitimi ve Spor Bilimleri Dergisi, 18(1), 71-80.

Tingaz, E.O. (2020). Spor bilimleri fakültesindeki sporcu öğrencilerde bilinçli farkındalığın (mindfulness) bazı değişkenler açısından incelenmesi. The Journal of Turkish Sport Sciences, 3(1), 21-28.

Vural, C., Okan, İ. (2021). Sporda bilinçli farkındalık: atıcılık spor branşları üzerine bir araştırma. Akdeniz Spor Bilimleri Dergisi, 4(2), 265-273. 


\section{EXTEND ABSTRACT}

\section{Investigation of Mindfulness Levels of High School Students in Terms of Different Variables}

Mindfulness has its origins in Buddhism, it is a state of focusing one's attention on the present without any judgment and accepting it. The process of directing attention to the events taking place at the moment can be defined as the concept of conscious awareness. Conscious awareness can be expressed as accepting and approving the present time without being influenced by previous or future events and emotions. Mindfulness is a method that involves focusing attention. Focusing on the present moment without judgment. This is the conscious development of attention. The orientations of mindfulness exercises include openness, comprehension, curiosity, and non-judgment. The main point in mindfulness is the acceptance of the felt or occurring situations as they are without any effort to change them. Since the individual is not accepted, it is seen that their pain is considered in terms of content from their own content. Consciously shows the individual a different path in such styles. Therefore, in this study, Investigation of mindfulnes Levels of High School Students in terms of Different Variables.

Descriptive survey model was used in the study because it was desired to reveal an existing situation. Descriptive survey models are research models that aim to reveal a past or present situation. In this context, the factors that are the subject of the research are defined as they are and they are concluded by observing appropriately. While the population of this research is Şahinbey district of Gaziantep province, the sample group consists of public schools that provide high school education under the Ministry of National Education. A total of 266 students, 140 women and 126 men, participated in the study.

In the study, a personal information form including gender, class level, sports branch, sports team she is a supporter, sport status and family income level and athlete mindfulness scale were used in the study. SPSS 22 package program was used for statistical analysis of the data. In order to determine the normality distribution of the data, skewness and kurtosis (Skewness and Kurtosis) values were examined and it was determined that it could show a normal distribution between $-2,0+2.0$. Descriptive analysis was conducted to determine the significant differences between the participants. The t-test was applied for two independent groups, and the one-way analysis of variance (ANOVA) test was applied for more than two groups. Tukey test, one of the pairwise comparison tests, was used to determine the significant difference between the groups in the results of one-way analysis of variance (ANOVA). The significance level was accepted as 0.05 .

As a result; T-test analysis was performed according to the gender variable and a significant difference was determined in the refocus sub-dimension. One-way analysis of variance (ANOVA) was applied according to the variables of class level, sport branch, sporting status and family income level, and in the analysis results, in the awareness sub-dimension according to the class level variable, in the refocus sub-dimension according to the sport branch and sporting status variable, family income level. variable, a significant difference was found in the sub-dimension of non-judgment. There was no significant difference in the sub-dimensions of the scale according to the variable of the sports team that the participants support. 


\section{(c) (i) (2) (2)}

"International Journal of New Approaches in Social Studies - IJONASS" is licensed under a Creative Commons Attribution-NonCommercial-ShareAlike 4.0 International License. 